\title{
THE ROAD MAP TO APPLY EVOLUTIONARY INTELLIGENCE TO ASPHALT PAVEMENT MODELLING
}

\author{
Reus Salini (1) \\ José Neves (2) \\ António Abelha (3) \\ Universidade do Minho \\ Campus de Gualtar \\ 4710 - 057 - Braga - Portugal \\ E-mail (1): R.Salini@gmx.net \\ E-mail (2): jneves@di.uminho.pt \\ E-mail (3): abelha@di.uminho.pt
}

\section{KEYWORDS}

Evolutionary Intelligence, Asphalt Pavement Modelling.

\begin{abstract}
Modelling the service life for asphalt pavements is widely made with base on empirical methods, developed half-century ago, with poor results. The new reality of the XXI century, with high construction costs, environmental restrictions and growing volumes of vehicles in the highways, enforce the shift to a new level of quality and accuracy to predict the service life of the pavements. This paper presents some insights either theoretical or experimental into a making from the ground, of an approach to predict and model the asphalt pavement behaviour using soft computing tools and, at the same time, create a way to accumulate the knowledge in this engineering field. The knowledge about the asphalt pavement life cycle is organized in a hierarchical way in order to be reused in a formal way, leading to an evolutionary process of adaptation and construction (Neves et al. 2007).
\end{abstract}

\section{INTRODUCTION}

Created in the old Roman Empire, the paved roads are at the center of a big revolution in the human history. The pavement allows any person, day or night, with raining or snow, to move between two locations in an effective way, helping to grow all human activities, as the commerce, the industry, the health sciences, just to name a few.

Thousands years after the Via Áppia was paved by the Romans, the most used methods for pavement modelling and design remain at an unbelievable empirical level. The studies based on fatigue tests made in the last half-century, after the introduction of the asphalt as material for highways, do not allow any true progress to understanding and modelling the asphalt pavement behaviour.
This empirism results in an early and high rate of failure in some pavements and, in anothers, over-design; both cases have a poor cost-effectiveness for the used money. The empiric approaches also do not provide any way to scientifically accumulate the knowledge, making hard for the pavement engineering use the experience of one highway in to another as the experience remain empirically accumulated in the persons, and can be easily lost due to forgetting, retirement or death.

The new challenges of the XXI century, with the growing quantity of the vehicles in the streets, growing capacity of load of the trucks, high costs of the materials used in pavements, high cost of the labour and the crescent environment restrictions to mining and the use of materials like stones, enforce the achievement of a new level in prediction of the service life and modelling the asphalt pavement behaviour (Flintsch 2003).

Due the ultra-complex behaviour of the asphalt pavement, quality modelling cannot be achieved with empirical or semi-religious approaches. A strong tool, able to handling all the necessary variables and its near infinite combinations need to be used. The soft computing approach to modelling may be in line to provide the necessary power to this task (Yang et al. 2003; Bosurgi and Trifirò 2005).

\section{THE SOURCE DATA}

In order to be able to use and reuse the knowledge available is necessary, first, to generate and organize the information about the performance of the pavement.

The initial step, and the first challenge, is in the instrumentation of a section of highway open to live-traffic, with sensors to register in a database and/or knowledge base all variable data believed as important and connected to the durability of the asphalt pavement. As its service life do not decrease in a linear or constant rate, the database need to register the information for one full cycle of the service life of the asphalt pavement, or in another words, to get data all along several years. 
The desirable variables to construct the database can be grouped in three areas: (a) environmental, (b) vehicles and (c) structural response of the pavement.

The asphalt pavement is subject of a well known influence of the environment, where the desirable variables are: air temperature, rainfall, wind speed, groundwater level, solar radiation, UV radiation and the pavement temperature.

The pavement is a structure subject to loads by vehicles, and the desirable variables in this arena are: vehicle counting, speed, classification and configuration by axle, and weight by axle.

The asphalt pavement has, in general terms, an asphalt concrete layer and a granular layer. To know how the pavement structure is performing under loads and with the influence of the environment, the desirable data are: asphalt layer vertical strains, asphalt layer pressures, asphalt layer horizontal strains, moisture in the granular layer, granular layer pressures and strains.

The Figure 1 shows the desirable variables in a chart format. Every time a vehicle crosses the instrumented section all sensors are read and the generated data is recorded in the database. The recording is only stopped when the pavement meets the end of the service life.

The criteria to the end of the service life can be anyone, technical, financial, functional or of any other nature. Also a multiple criteria can be used with this method and, in this case, the data need be recorder until the last criteria is meeting. For each criteria the database will be "cuted" in a different point and a new matrix of data is created.

\section{THE CONSTRUCTION OF THE KNOWLEDGE}

With the database already built, the next step is to compile the information available to another language, a math language (Figure 2). This is a fundamental step in order to make easy handling of the data to fix the importance of each variable and its interaction to the pavement durability.

The data need be organized in a form of a matrix, with one line per vehicle.

Now, one has to calculate the relative relevance of each variable and the relative importance of each vehicle for the pavement service life in a consistent way, which is the second challenge in this method. This can be solved using one or more topologies based on Evolutionary Intelligence like evolutive-genetic algorithms, logic-mathematic functions or particle-swarm optimization and, if the translation of the field data to the math is made in a consistent way, a matrix of equations will be generated, which may be solved with traditional approaches. A combination of Evolutionary Intelligence and matrix of equations can also be used to find the best possible classification for the lines (Mendes et al. 2004; Rocha et al. 2005; Rocha et al. 2006).

Once this task have been solved, every line in the matrix of data receives a "pavement damage" index representing the relative importance of the line in relation to the other ones (Figure 3 ).

It must be pointed out that the importance of the individual variables in the line is useful in order to testify the consistence of the solution of the matrix, but it is not critical information for this method.

The Figure 4 shows the diagram with the tasks to transform the source "brute" data to an information fine to train a neural network system.

The knowledge can be easily accumulated just adding new sets of field data to the initial database. The accumulation allows continuous improvement in the accuracy and usability.

\section{HANDLING THE ERRORS}

Regardless the used tools - matrix of equations and/or Evolutionary Intelligence based tools and/or computational topologies - some level of error will remain in the final pavement damage index. The third challenge is to handle this error in an efficient way.

The data obtained in the previous tasks that lead to the pavement damage index, is to be understood as the result of the "true" damage multiplied by an error (Figure 5).

At this stage of the development of the method it is not possible to know if there exist some way to calculate and isolate this error or not. In any case, an excellent solution to handling it was found.

The error can have any size if it is well distributed inside the matrix, or in another words, if the error in the pavement damage index in the line 1 is similar to the error in the line 2, and so on. As the result, the sum of the pavement damage indexes for the full matrix will have the same similar error.

Instead to use the pavement damage index as an absolute value, in this approach it is used in a comparative way, with the individual pavement damage index divided by the sum of the damages; as the error exists in both, the error is divided by itself and eliminated (Figure 6).

Handling the error in this way it helps the calculus of the pavement damage indexes, once it allows the use of 
some tips, as mix artificial data with true field data, in order to potentiate an easy convergence and a better solution for the matrix. The only rule to be accommodated is: the error need to be well distributed inside the matrix.

\section{TRAINING THE NEURAL NETWORK}

The matrix of knowledge made in a consistent way and ready to be used is named "matrix of performance", a source of "intelligence" to train a neural network system.

The only challenge in this step is the computer power to train a so big matrix of data, with dozen of millions of data items.

On the other hand the neural network has to be trained until one is be able to do predictions with a realistic accuracy. This can be easily checked just proposing lines of the matrix of performance as problems to be solved. The neural network will be well trained if found a pavement damage index similar to the one in the matrix of performance for the same lines.

The Figure 7 shows a chart with the matrix of performance and a pavement design proposed as a problem to the trained neural network evaluates the pavement damage.

\section{VALIDITY AND USE OF THE MODEL}

The matrix of performance can be used to evaluate the damage to pavements constructed with the same materials used in the instrumented test section used as a data source to the initial database.

The Figure 8 shows how to use the trained neural network to do predictions about the pavement service life. The problem need be proposed in the exact same format used to construct the matrix of performance and with the same information, including data about the environment, vehicles and pavement structural response. The data about the environment can be easily found with meteorological institutes and the vehicles can be counted, for existing highways, or evaluated with traditional procedures, for new highways. For new pavements the structural response can be calculated with finite elements procedures; for existing highways can be calculated with a combination of non-destructive tests (FWD, Benkelman Beam, etc.) and finite elements.

The Figure 9 shows a comparison between the approach here proposed and the equation of fatigue, the current state-of-the-art.

\section{CONCLUSIONS}

It is shown in Figure 9 that the (state-of-the-art) technology used in asphalt pavement modelling and design is based on the "equation of fatigue", an empirical-archaic approach that does not meet the requirements of the XXI century needs.

The approach proposed herein is based on soft computing tools leading, to:

- The establishment, for the first time in the pavement engineering, of a viable way to use strictly scientific procedures to model and predict the asphalt pavement behaviour and service-life, taking into consideration all problem variables;

- A change of paradigm with the potential to provide asphalt pavement modelling with unprecedented level of accuracy and reliability, with no subjective or empirical influence;

- The creation of an efficient and suitable form to knowledge gathering, allowing its use and reuse to optimize the accuracy and expand the usability of the model in a continuous way.

\section{REFERENCES}

Bosurgi, G. and Trifirò, F. A Model Based on Artificial Neural Networks and Genetic Algorithms for Pavement Maintenance Management. International Journal of Pavement, Vol. 6, No. 3, pp. 201-209, 2005.

Flintsch, G.W. Soft Computing Applications in Pavement and Infrastructure Management: State-of-the-Art. Transportation Research Board Annual Meeting, 2003.

Mendes, R.; Kennedy, J. and Neves, J. The Fully Informed Particle Swarm: Simpler, Maybe Better, Journal of the IEEE Transactions of Evolutionary Computation, 2004.

Neves, J.; Machado, J.; Analide, C.; Abelha, A. and Brito, L. The Halt Condition in Genetic Programming. In Lecture Notes in Artificial Intelligence 4874 - Progress in Artificial Intelligence - Springer, 2007.

Rocha, M.; Cortez, P., and Neves, J. Simultaneous Evolution of Neural Network Topologies and Weights for Classification and Regression. In Lecture Notes in Computer Science 3512, Proceedings of the IWANN Conference, Barcelona, Springer, 2005.

Rocha, M.; Cortez, P. and Neves, J. Evolution of Neural Networks for Classification and Regression. Neurocomputing, Elsevier, 2006.

Yang, J.; Lu, J. J.; Gunaratne, M. and Xiang, Q. Overall Pavement Condition Forecasting Using Neural Networks: Application to Florida Highway Network. 82nd Annual Meeting of the Transportation Research Board, Washington, D.C., 2003. 


\section{AUTHOR BIOGRAPHIES}

REUS SALINI, Gaúcho born at the Rio-Grandense Republic. Has received the award for first place in the Civil Engineering course at Santa Catarina State University (Brazil); obtained his Master of Science course in Highway Engineering at the Federal University of Santa Catarina (Brazil). Works as pavement and highway designer engineer since 1995 with strong focus on innovative solutions. His e-mail is R.Salini@gmx.net and Skype username is "sukhoi47".

JOSÉ NEVES was born in Vila do Conde, Portugal, and went to the University of Coimbra, Portugal, where he studied chemical technology and obtained his degree in 1976. He worked for a couple of years at the University of Minho, Braga, Portugal, and then went to Heriot-Watt University, in Scotland, where he got a MSc degree in Software Development and Analysis, and a PhD degree in Logic Programming and Data Bases. He is now full Professor at the University of Minho, Braga, Portugal, where he leads the Artificial Intelligence Group. His main interests are in the area of Knowledge Representation and Reasoning, Evolutionary Intelligence and Logic Programming.

ANTÓNIO ABELHA was born in Vila do Conde, Portugal, and went to the University of Minho, Portugal, in 1982, where he studied Informatics. He worked from 1993 at the University of Minho, Braga, Portugal, where he got a MSc degree in Computer Science, and a PhD degree in Artificial Intelligence. He is now Auxiliary Professor at the University of Minho, Braga, Portugal, in the Artificial Intelligence Group. His main interests are in the area of Knowledge Representation and Reasoning, Logic Programming and Data Bases, and Simulation.

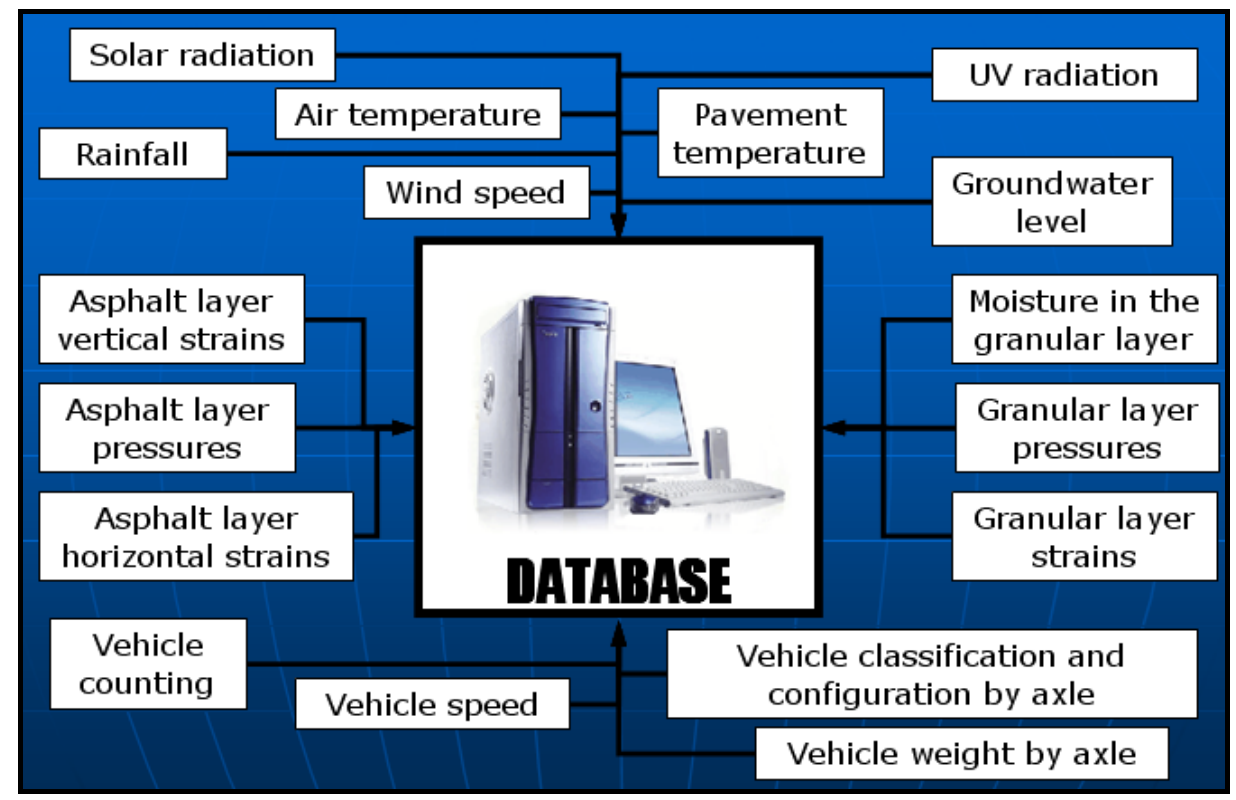

Figure 1: Desirable Variables to a Database Suitable for Asphalt Pavement Modelling Using Artificial Intelligence

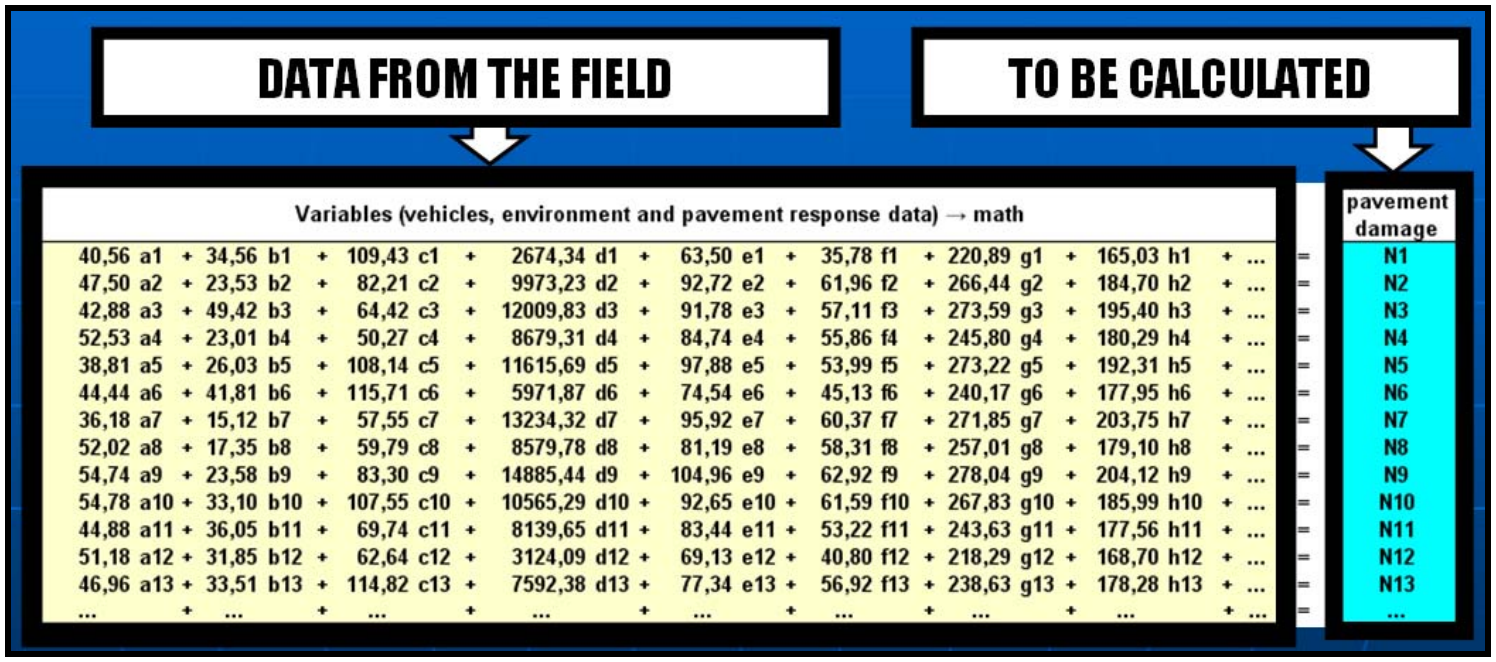

Figure 2: Field Data Organized in Form of a Matrix of Numbers 


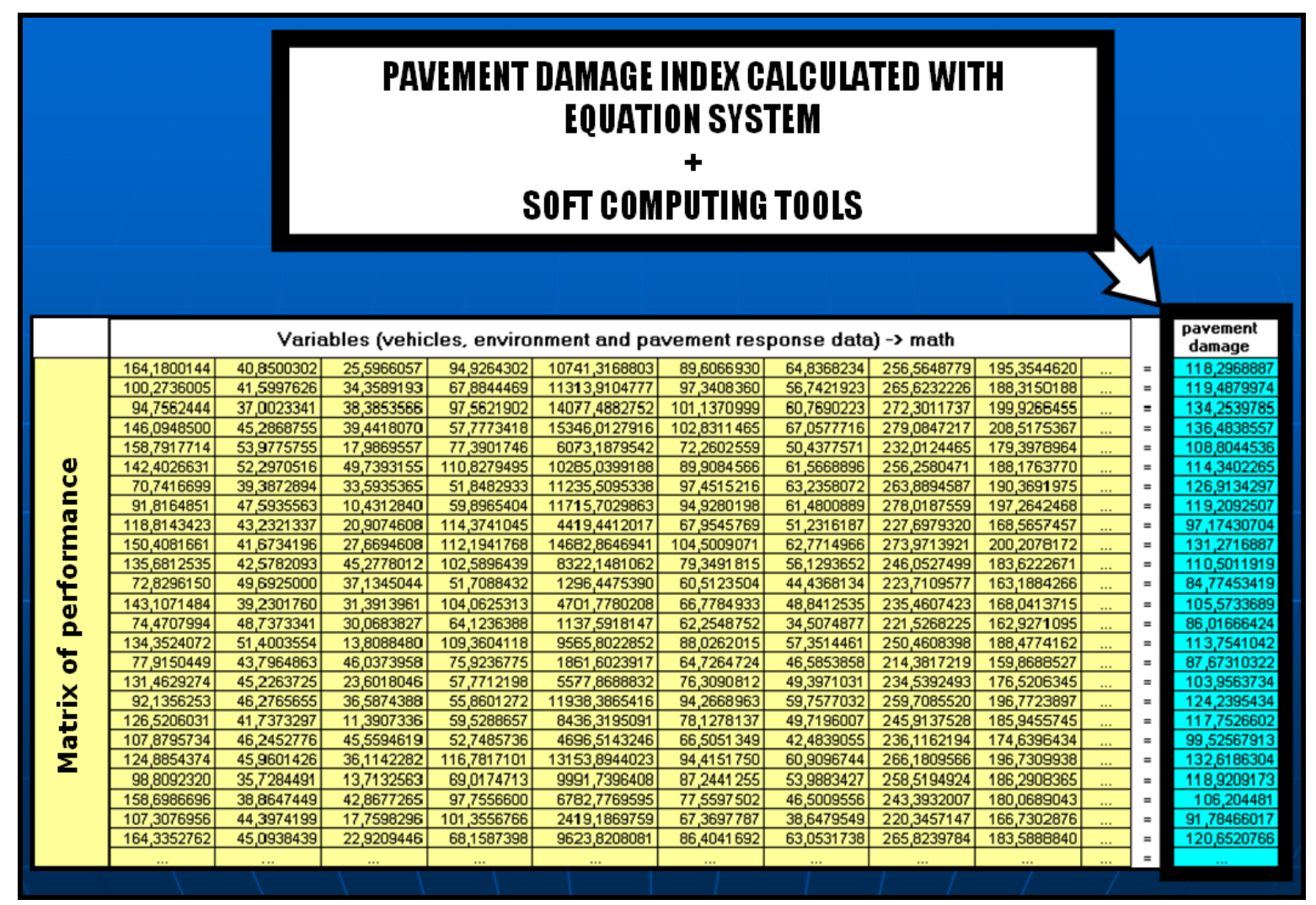

Figure 3: The Pavement Damage Index Calculated

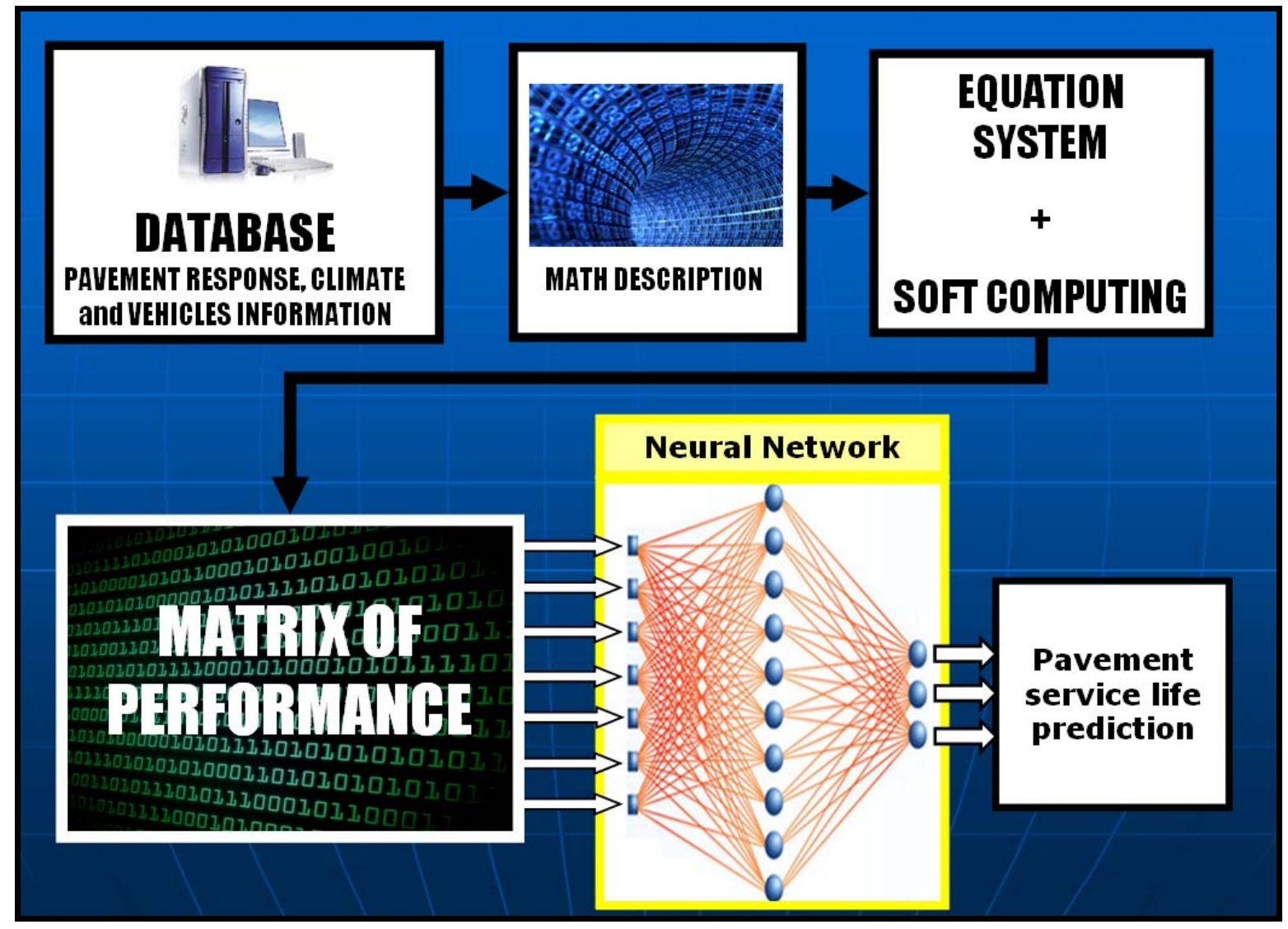

Figure 4: The Database With the History of the Pavement is "Handled" to Become a Matrix of Performance to Train the Neural Network System 


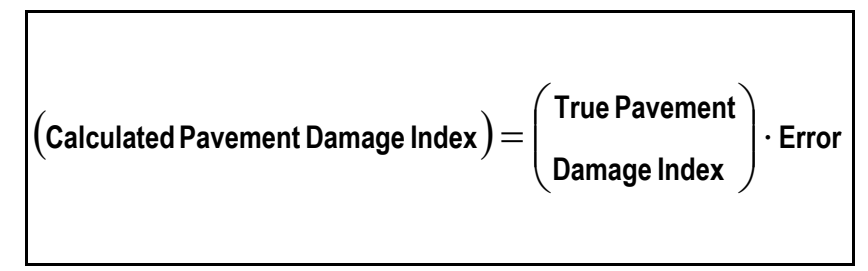

Figure 5: The Found Pavement Damage Index has an Unknown Error

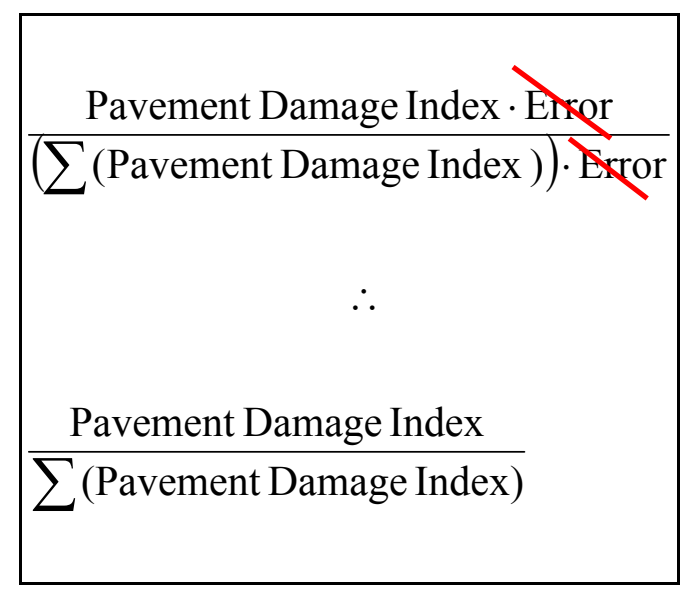

Figure 6: The Error is Divided by Itself and Eliminated

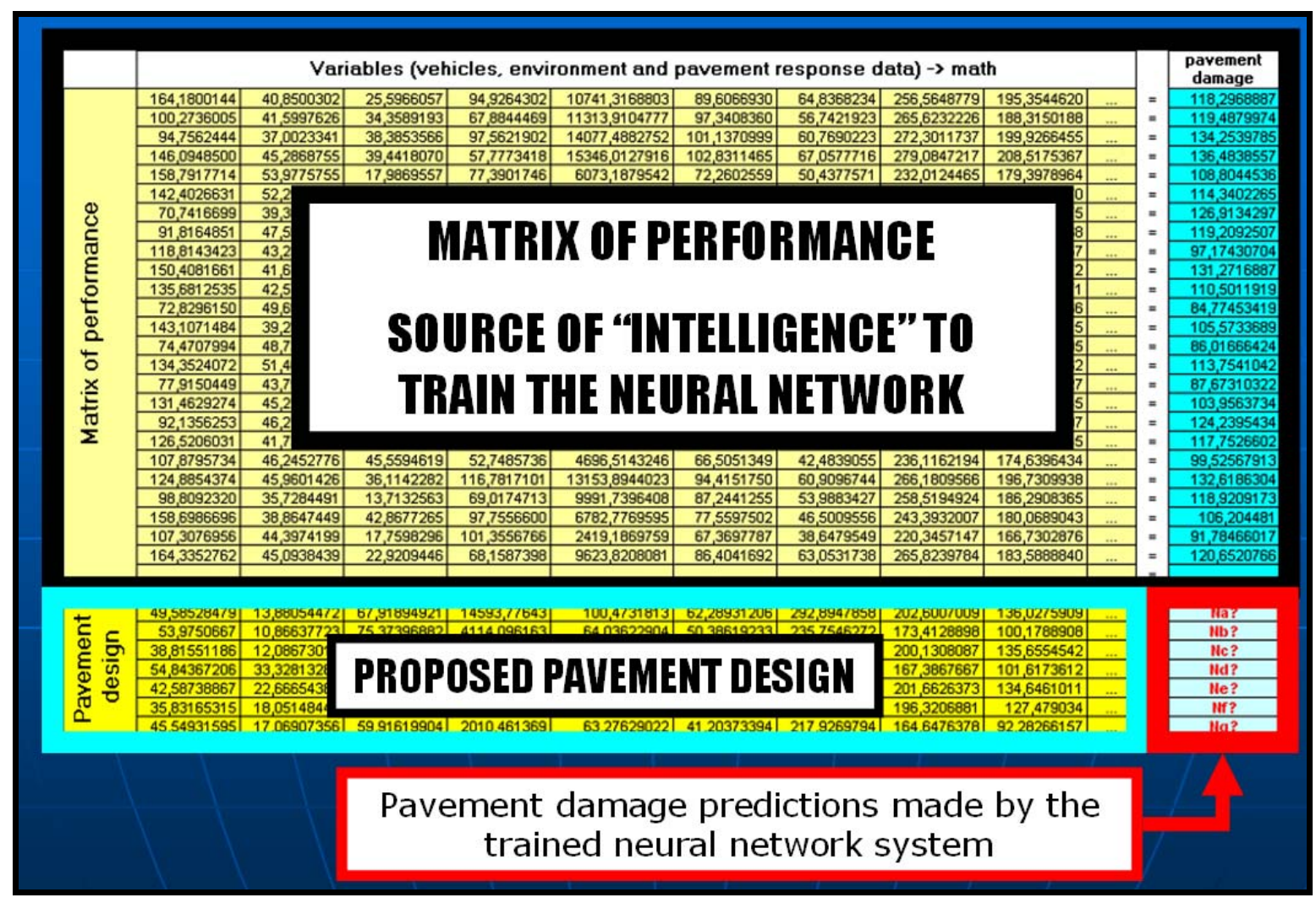

Figure 7: The Neural Network Will be Able to Do Predictions for Problems Proposed in the Exact Same Way Was Described the Initial Database Used to Generated the Matrix of Performance 


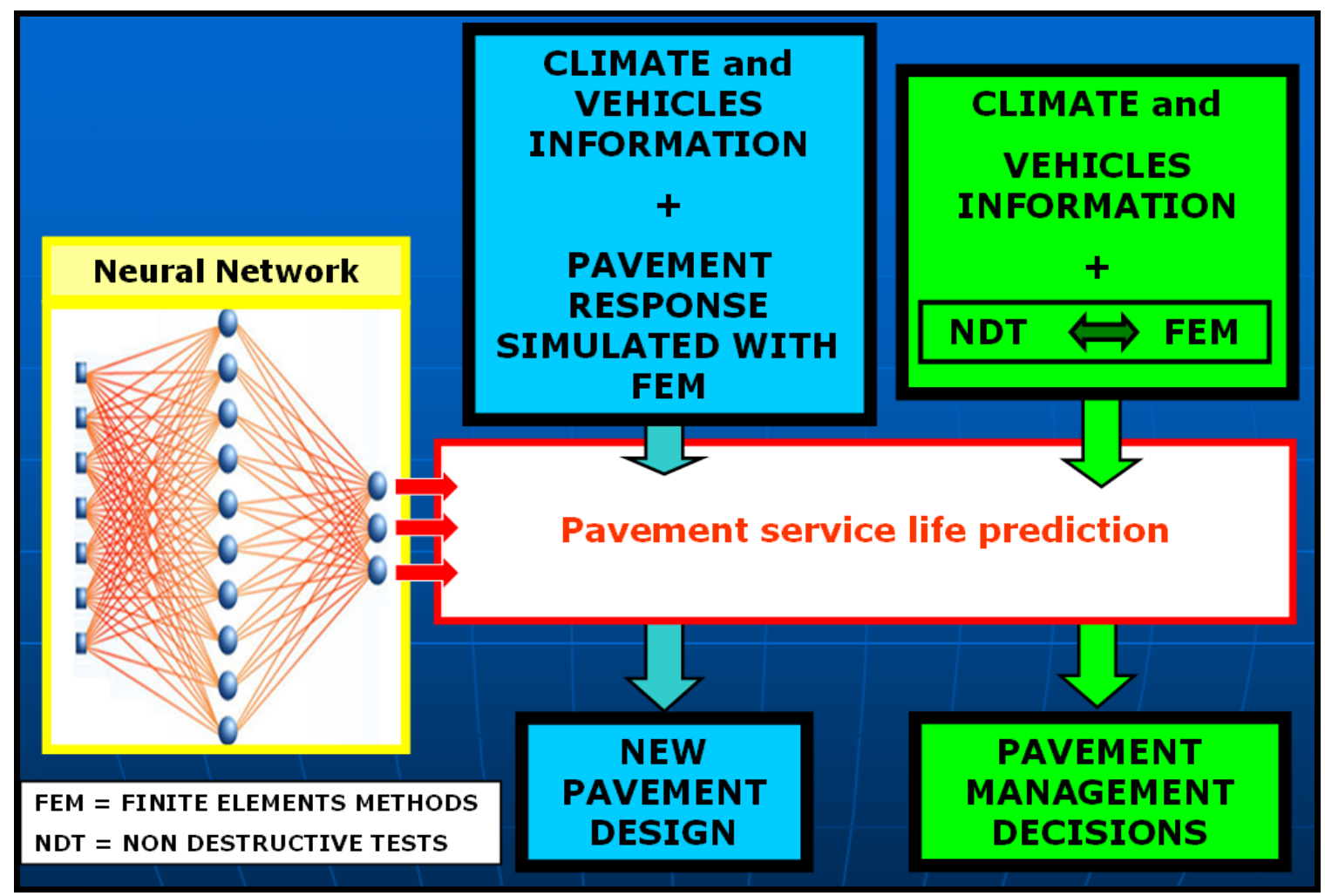

Figure 8: The Trained Neural Network System Will do Predictions About the Service Life for Both, Design New Pavements and Take Decisions in a Pavement Management System

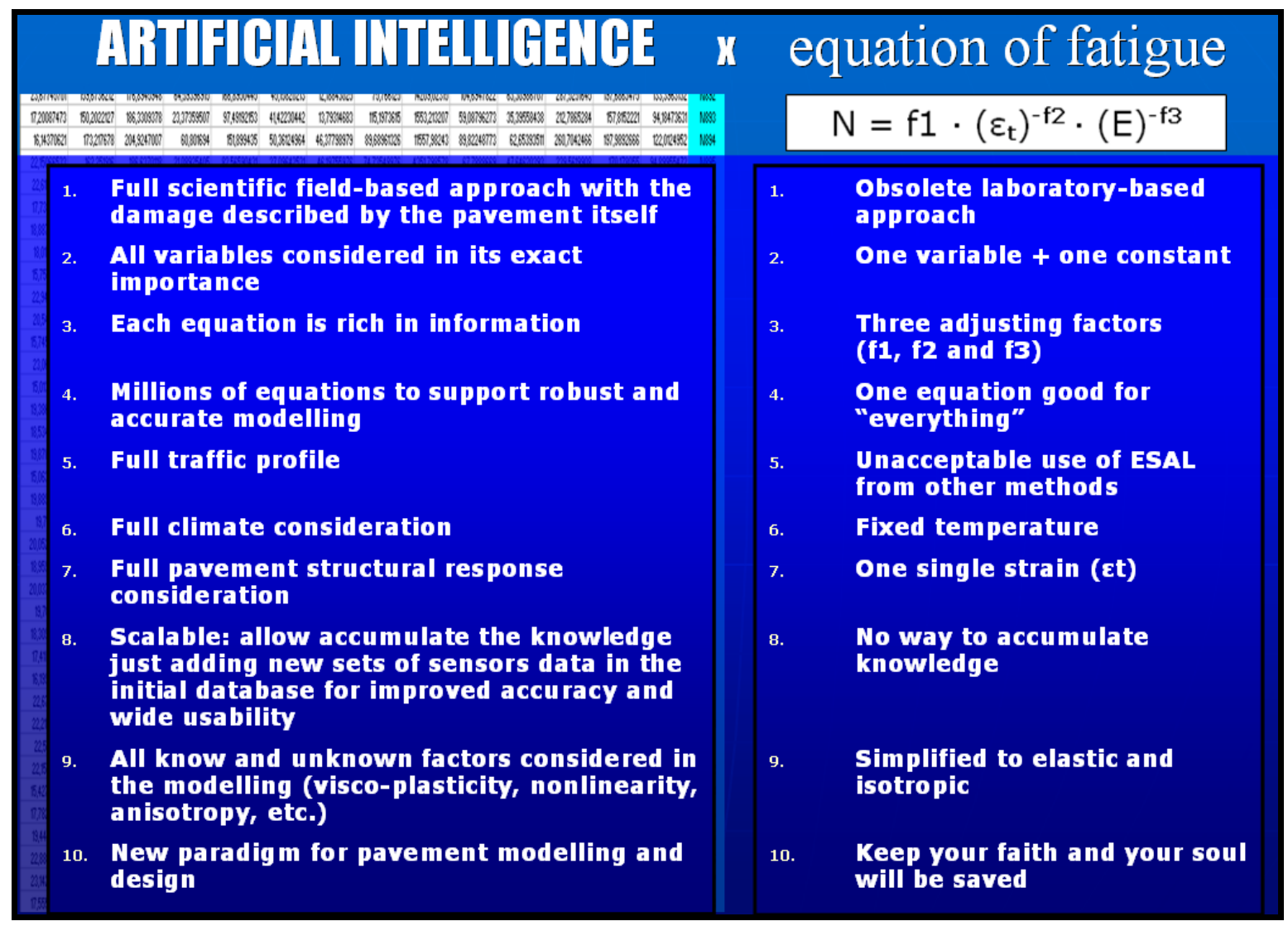

Figure 9: Comparison Between the Modelling Using Neural Network Trained With the Matrix of Performance Against the Current "Technology" of The Equation of Fatigue 